\title{
Diagnostic Utility of Cell Block Technique as an Adjunct Technique to Cytological Smears in Evaluation of Thyroid Aspirates on Fine Needle Aspiration Cytology
}

\author{
Amreek Lal', Siyab Ahmad², Waseem Khan', Liaqat Ali², Mian Anwar Zeb², Farhana Shaheen ${ }^{2}$
}

\section{ABSTRACT}

Background: Fine needle aspiration cytology is a standard screening technique for the diagnosis and assessment of thyroid nodules. However, this approach has some drawbacks, such as false negative or positive outcomes and high rates of unsatisfactory results.

Objective: To describe the utility of cell block technique as an adjunct to conventional smear in the cytodiagnosis of thyroid epithelial lesions.

Material and Methods: This Descriptive Cross-sectional study was done at the Pathology department of Saidu Group of Teaching Hospital Saidu Sharif Swat from $1^{\text {st }}$ November 2017 to $31^{\text {st }}$ April 2018 . Fine needle aspirates for both the direct smear and cell block were collected simultaneously from 60 patients, through non- probability convenient sampling. All patients having clinically enlarged thyroid, solitary or dominant thyroid nodule were included in the study. All patients below 22 years old and patients who did not give informed consent were excluded. Ethical clearance was obtained from the ethical research committee before carrying out the study. Written informed consent was taken from all the participating patients.

Cellularity, obscuring background material, morphological and architectural preservation as well as cytodiagnosis on direct smear and cell block technique were compared. Data were analyzed using SPSS software version 21. McNemar's chi-square test was applied for significant difference. $P$-value of $=0.05$ was considered significant.

Results: Male to Female ratio was 1:7.5, (13\%: 87\%). The age ranged from 22 to 81 years with a mean age of 44.9 and standard deviation of \pm 14.5 years. The study showed that the cell block technique has high cellularity, minimal obscuring background, better architectural preservation and poor morphological preservation on cell block in comparison to direct smear. The majority of the cases were benign on both techniques. The unsatisfactory rate was reduced in cell block technique and showed additional information in $13 \%$ cases.

Conclusion: The study demonstrated no significant difference in the diagnostic utility of both techniques.

Keywords: Cell Block Cytopathology, FNAC, Mair et al criteria,

This article may be cited as: Lal A, Ahmad S,Khan W, Ali L, Zeb MA, Shaheen F. Diagnostic Utility of Cell Block Technique as an Adjunct Technique to Cytological Smears in Evaluation of Thyroid Aspirates on Fine Needle Aspiration Cytology. J Saidu Med Coll Swat 2021;11(4):217-22.DOl:https://doi.org/10.52206/jsmc.2021.11.4.682

\section{INTRODUCTION}

The incidence of thyroid nodules in the general adult population varies from $4 \%$ to $7 \%$ and in children from $0.2 \%$ to $1.2 \%$. Most of these nodules are benign, and about $5 \%$ to $15 \%$ are malignant. ${ }^{1}$ The key goal of assessing these nodules is to differentiate benign nodules from malignant ones. Ultrasound and nuclear scanning can also be used in combination with FNAC.

In the evaluation of the thyroid nodule, FNAC is known to be the gold standard screening test. FNAC is a reliable, simple, easy-to-repeat and cost-effective procedure with excellent patient compliance. ${ }^{3}$ The FNAC, however, has limitations. Some of the limitations include false negative or positive results. Besides, FNAC cannot define malignant follicular lesions in the absence of papillary carcinoma nuclear features. These limitations are due to compromised specimens which are not well preserved and may be due to sparsely cellular or excessive clotting. Like other

1. Saidu Medial College Saidu Sharif Swat.

2. Swat Medial College Marghuzar Swat.

Correspondence: Dr. Siyab Ahmad

Department of Pathology

Swat Medical College, Marghuzar Swat.

E-mail: siyabamc@gmail.com

Received: November 22 $2^{\text {th }}$, 2019 Accepted: August 26 $6^{\text {th }}, 2021$ conventional FNA smear, thyroid FNAC also offers limited material for ancillary tests. ${ }^{4}$

Cell block preparation is known to increase cellular yields and improve diagnostic accuracy. Cell blocks are micro biopsies embedded in paraffin wax, suitable for sectioning, staining and microscopic studies. ${ }^{5}$ Cell Block enables the recovery of small tissue fragments to be processed as a histological tissue biopsy. It also offers extra material for other ancillary tests i.e. immunocytochemistry and cytogenetics etc. ${ }^{6}$ Just like paraffin tissue sections in histology, cell block section yields histologic cytological architecture which are useful when making diagnosis. Architectural pattern may not be present on conventional smear. However, Cell Block techniques has some limitation such as increased cost and lengthened turnaround time. ${ }^{7}$ The objective of our study is to describe the utility of cell block technique as an adjunct to conventional smear in the cytodiagnosis of thyroid lesions.

\section{MATERIALAND METHODS}

This cross-sectional study was carried out at the Pathology department of Saidu Group of Teaching Hospital Saidu Sharif from $1^{\text {st }}$ November 2017 to $31^{\text {st }}$ April 2018. A total of sixty cases were included in the study. Non-Probability convenient sampling 
method was used. Approval for the study was taken from the Ethical Approval committee.

The study included patients from all ages and from both genders that have Palpable or diffusely enlarged thyroid gland. Patients not willing for fine needle aspiration cytology of their thyroid lesions, after explaining the purpose and utility of the procedure were excluded. Patients with thyroid lumps were referred to the pathology department from surgical outpatient department with a prerequisite FNAC form. Bio demographic data was collected on a data collection form. Written informed consent was taken from each patient.

A standard procedure of fine needle aspiration was followed and a 22-23-gauge needle and a 5 $\mathrm{ml}$ syringe was attached incase the aspirate was fluid. Two clean labelled slides were used to prepare smears. Slides were fixed immediately in $95 \%$ alcohol for a minimum of 15 minutes and stained with hematoxylin \& eosin stain according to the standard procedure.

Cell blocks were either made from an additional pass and/or remnant aspirate in the needle hub and syringe. Needle rinses in alcohol formalin fixative $(50 \%$ of $95 \%$ ethyl alcohol and $10 \%$ formalin each) and then was centrifuged at 1500 rpm for 3-4 minutes. The supernatant was discarded and further $3 \mathrm{~mL}$ of fresh fixative added and kept for one day. The cell button was scooped out and processed as a routine surgical specimen and stained with hematoxylin and eosin stain. Both smears and blocks were reviewed by two consultant histopathologists independently.

Qualitative assessment of both slides was graded according to the Mair et al criteria ${ }^{8}$ i.e. cellularity, obscuring background material, degree of cellular degeneration and architectural preservation. The data was analyzed by using SPSS version 21 . Frequencies and percentages were calculated for the categorical variable data and mean and SD for numerical data. McNemar's chi square test was applied for significant difference. $P$ value $=0.05$ was considered significant.

\section{RESULTS}

The patient age range was from 22 to 81 years with age mean of 44.9 years and standard deviation of 14.5 years. Majority of patients $(28.3 \%)$ were in their third decade of life followed by $20 \%$ of patients in their fourth decade. (Fig1) The largest numbers of patients were females accounting for $87 \%$ (52/60) of total participants.

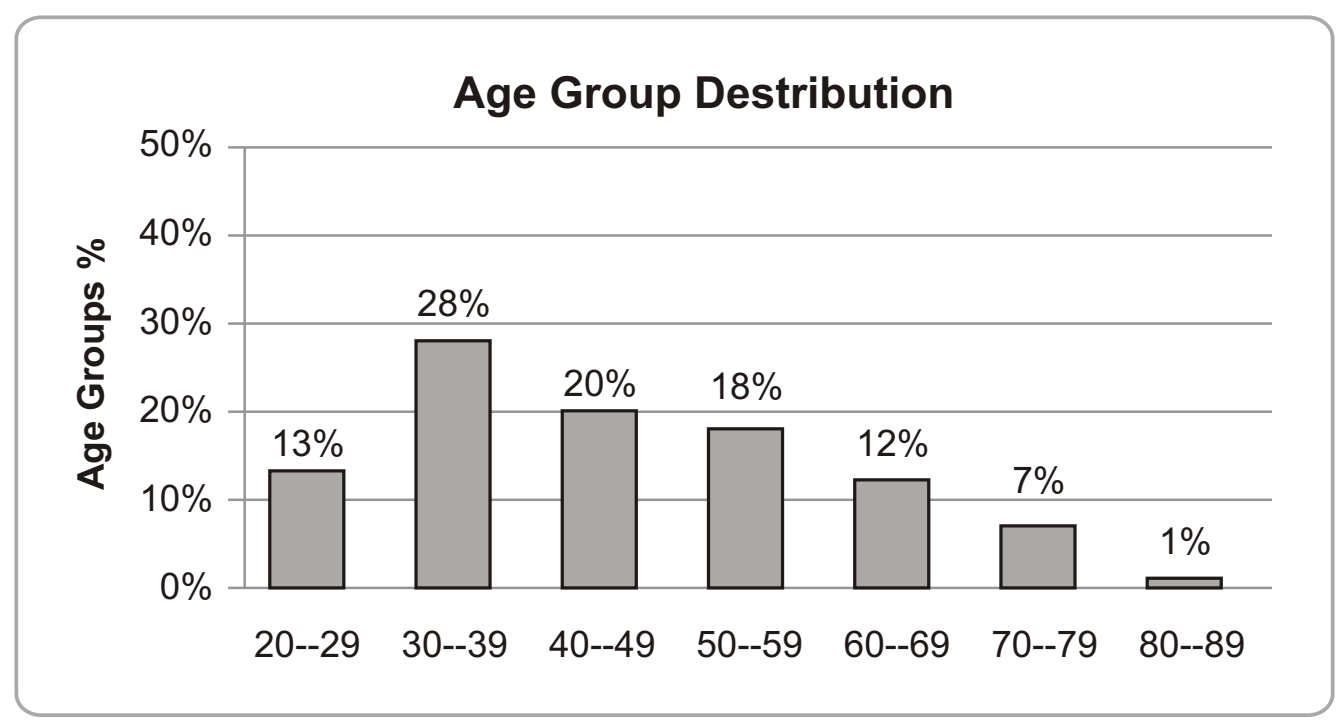

Figure 1: Histogram showing age group distribution.

The majority of patients (38.4\%) had thyroid gland enlargement for the period of one to twelve months. $13.4 \%$ of the participants were not able to recall its duration. (Fig. 2) 


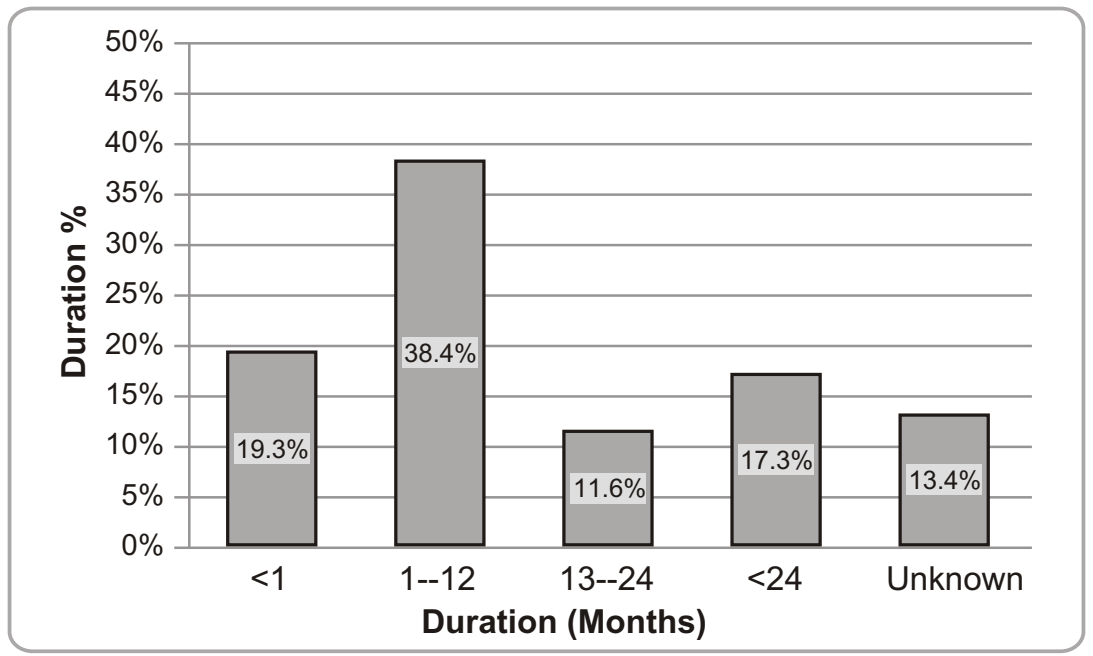

Figure 2: Duration of thyroid lesions among patients.

Assessment of both methods using Mair et al scoring system.

The two methods (conventional and cell blocks) were assessed qualitatively by using Mair et al scoring system for assessing the quality of the slides into four categories: background obscuring material, cellularity, cellular degeneration and architectural and cellular arrangement as summarized (Table 1)

Table 1. Mair et al scoring system comparing both methods

\begin{tabular}{|c|c|c|c|c|}
\hline \multirow[b]{2}{*}{ Mair et al Category } & \multicolumn{2}{|c|}{ Conventional Smears } & \multicolumn{2}{|c|}{ Cellblock } \\
\hline & $\begin{array}{c}\text { Parentage } \\
(\%)\end{array}$ & $\begin{array}{l}\text { Frequency } \\
\text { (n) }\end{array}$ & $\begin{array}{c}\text { Parentage } \\
(\%)\end{array}$ & $\begin{array}{c}\text { Frequency } \\
\text { (n) }\end{array}$ \\
\hline \multicolumn{5}{|l|}{ CELLULARITY } \\
\hline Minimal (A Scored 0) & $28.3 \%$ & 17 & $20.0 \%$ & 12 \\
\hline Sufficient (B Scored 1) & $48.3 \%$ & 29 & $45.0 \%$ & 27 \\
\hline Abundant (C Scored 2) & $23.3 \%$ & 14 & $35.0 \%$ & 21 \\
\hline \multicolumn{5}{|c|}{ OBSCURING BACKGROUND MATERIALS } \\
\hline Minimal (C Scored 2) & $13.3 \%$ & 8 & $20.0 \%$ & 12 \\
\hline Moderate (B Scored 1) & $51.6 \%$ & 31 & $50.0 \%$ & 30 \\
\hline Marked (A Scored 0) & $35.1 \%$ & 21 & $30.0 \%$ & 18 \\
\hline \multicolumn{5}{|c|}{ DEGREE OF CELLULAR DEGENERATION } \\
\hline Minimal: good preservation (2) & $66.7 \%$ & 40 & $51.7 \%$ & 31 \\
\hline Moderate: diagnosis possible (1) & $15 \%$ & 9 & $18.3 \%$ & 11 \\
\hline Marked: diagnosis impossible (0) & $18.3 \%$ & 11 & $30.0 \%$ & 18 \\
\hline \multicolumn{5}{|c|}{ ARCHITECTURE ARRANGEMENT } \\
\hline Minimal (A Scored 0) & $55.0 \%$ & 33 & $36.6 \%$ & 21 \\
\hline Moderate (B Scored 1) & $40.0 \%$ & 24 & $51.6 \%$ & 31 \\
\hline Excellent (A Scored 0) & $5.0 \%$ & 3 & $11.6 \%$ & 8 \\
\hline
\end{tabular}


Diagnostic Utility of Cell Block Technique as an Adjunct Technique to Cytological Smears .....

\section{Cytodiagnosis Results}

Both cell block and conventional smears were reported using the Bethesda System of Reporting Thyroid cytopathology (Table 2).

Table 2. Frequency Table of Cytodiagnosis according to Method

\begin{tabular}{|l|c|c|}
\hline \multicolumn{1}{|c|}{ Results } & Conventional Smear (\%) & Cell Block (\%) \\
\hline Unsatisfactory & $17(28.3 \%)$ & $19(31.6 \%)$ \\
\hline Colloid Goiter & $38(63.3 \%)$ & $37(61.6 \%)$ \\
\hline Thyroiditis & $2(3.3 \%)$ & $1(1.6 \%)$ \\
\hline ACUS & $1(1.67 \%)$ & $0(0.0 \%)$ \\
\hline SFN & $0(0.0 \%)$ & $0(0.0 \%)$ \\
\hline Suspicious for Malignant & $0(0.0 \%)$ & $0(0.0 \%)$ \\
\hline Malignant & $2(3.3 \%)$ & $2(3.3 \%)$ \\
\hline Total & $\mathbf{6 0 ( 1 0 0 \% )}$ & $\mathbf{6 0}(\mathbf{1 0 0} \%)$ \\
\hline
\end{tabular}

Unsatisfactory results were reported in 28.3 per cent cases of conventional smear and slightly higher (31.6 per cent) in cell block section. Among the 17 samples that were unsatisfactory on conventional smears, 8 samples were satisfactory on cell block method preparation. Two cases of lymphocytic thyroiditis were reported on conventional smears while cellblock reported one case of thyroiditis and another one was unsatisfactory.

Colloid goiters were reported in 63.3 per cent and $66.6 \%$ in conventional smear and cellblock cases respectively. One case that was reported as atypical cell of undetermined significant on conventional smear was unsatisfactory on cellblock. There were two case of malignant/ suspicious for malignant (anaplastic carcinoma) on both conventional and cellblock.

For Comparing the utility of the Cytology and Cell block method, McNemar test was employed for comparing adequate plus excellent samples $(A(2)$ plus $B(1)$ scored) with inadequate samples (C (0) scored), $p$ values were 0.289 (more than 0.05 ) in both sessions, indicating a non-significant difference between the two techniques. $P$ values less than 0.05 were considered significant.

\section{DISCUSSION}

In this study, a total of 60 patients were recruited from Pathology department of Saidu Group Teaching Hospital Saidu Sharif Swat. Patient age ranged from 22 to 81 years with an average age of 44.9 years. This age range and mean occurrence is slightly higher than in the Manoj $\mathrm{G}$ et $\mathrm{al}^{9}$ study, who found that the age range was 22 to 58 years with a mean age of 38.7 years. It indicates that thyroid nodules are present across a wide age range. In this study, the majority of patients (28.3 per cent) were in their third decade of life, followed by 20 per cent of patients in their fourth decade. This is comparable to the findings of the Manoj G et $\mathrm{al}^{9}$ study, which showed that the majority of patients were in in their third decade of life.

The majority (52/60) of participants in this study were female, accounting for 87 per cent of the total participants with a male-to - female ratio of 1:7.5. This result is consistent with Bagga et $\mathrm{al}^{10}$ and Manoj $\mathrm{G}$ et $\mathrm{al}^{9}$, whom found that thyroid nodules were 4 to 9 times more common in females compared to males.

Marked cellularity was recorded in 35 per cent $(21 / 60)$ and 23.3 per cent $(14 / 60)$ for cellularity in cell block cases and in conventional smears. Marked cellularity in the cell block may be attributed to the clots in the needle hub that trap the cells and these clots were removed for the preparation of the cell block. It is compatible with Basnet et $\mathrm{al}^{11}$, which has shown that the cell block process allows for the recovery and processing of minute quantities of cells and thus high cellularity. 
Thirty-five (35.1 per cent) of conventional smears had marked obscuring background on the Mair et $\mathrm{al}^{8}$ score system, while only 30 per cent were documented to have marked obscuring background on the cell block Nevertheless, 20 per cent of cell block cases had a clear background (minimum obscuring background) compared to 13.3 per cent of conventional cases. The disparity can be accounted for because the cell block needs centrifugation of the fluid that enables the cell to settle.

The degree of cell degradation was similar in both techniques with minimal degradation rate of 66.7 per cent and 51.7 per cent on conventional and cell block cases respectively, although marked cellular degradation was higher in cell block 30 per cent than in conventional smears 18 per cent. This finding is in accordance with analysis of Khan. S et $\mathrm{al}^{12}$. The cause for this may be that the material for the cell block were processed after 3 to 4 times of the aspirations for the conventional smear and this may have contributed to poorly preserved specimen.

Cell block showed 11.6 per cent marked architecture and cellular arrangement compared to 5 per cent in conventional smears. Fifty five percent (33/60) had a minimal architectural arrangement on conventional smears as compared to 36.6 per cent in cellblock. This agrees with Balassanian $\mathrm{R}$ et $\mathrm{al}^{13}$ and Kulkarni et $\mathrm{al}^{14}$ which concluded that cell block retains architecture pattern with excellent nuclear and cytoplasmic details.

Twenty-eight percent of conventional cases were reported as unsatisfactory. This is a high unsatisfactory rate. Most studies have shown that the unsatisfactory rate differs from 2 to 20 percent. The high unsatisfactory rate in this study may be attributed to the fact that almost all FNA procedures were performed by pathologists of varying experience. Out of the two cases reported as chronic thyroiditis on conventional smear, only one case was thyroiditis, while the other case was unsatisfactory on cell block. Two cases were diagnosed as malignant / suspicious for malignant (anaplastic carcinoma) in both cell block (3.3 per cent) and conventional (3.3 per cent).

The majority (67.1 per cent) of the cases were identified as benign. This compares quite well with Cibas $\mathrm{E}$ et $\mathrm{al}^{15}$ who documented that 70 per cent of all thyroid FNA are reported as benign. Overall cell block aid in diagnosis of 8 cases (13.3 per cent) which is in concordance with Brown $\mathrm{K}$ et $\mathrm{al}^{16}$ and Thapar M. et $\left.a\right|^{17}$ who showed in their studies that cell block helped in diagnosis of 14 per cent and 13 per cent of cases, respectively.

\section{CONCLUSION}

This study showed a significant difference between the two techniques with regard to the four assessment parameters of conventional and cell block scores, but there is no statistically significant difference in the diagnostic utility of the two methods. In addition, the cell block provided additional information that was helpful in confirming and establishing a new diagnosis.

\section{LIMITATIONS AND RECOMMENDATIONS}

Patients have been recruited from two centres; a multicenter analysis with an improved sample size should be performed. Cell block method should be considered as an adjunct test for conventional FNA cytology of thyroids lesions, particularly neoplasms. In a resource constrained sitting, the cost of the procedure should be kept in mind relative to the affordability of the patient.

\section{REFERENCES}

1. Damle GK, Daharwal AV. Diagnostic accuracy of fine-needle aspiration cytology in diagnosis of thyroid nodules. Int J Res Med Sci. 2017;5(1):106112.

2. Pothier DD, Narula AA. Should we apply suction during fine needle cytology of thyroid lesions? A systematic review and meta-analysis. Ann R Coll Surg Engl. 2016;88(7):643-655.

3. Tauro LF, Lobo GJ, Fernandes H, George C, Aithala PS, Shenoy D, et al. A comparative study on fine needle aspiration cytology versus fine needle capillary cytology in thyroid nodules. Oman Med J. 2012;27(2):151-156.

4. Pinki P, Alok D, Ranjan A, Chand MN. Fine needle aspiration cytology versus fine needle capillary sampling in cytological diagnosis of thyroid lesions. Iran J Pathol. 2015;10(1):47-53.

5. Jain D. Mathur SR. Lyir Sk. Cell blocks in cytopathology: a review of preparative methods, utility in diagnosis and role in ancillary studies. Cytopathology. 2014;25(6):356-371.

6. Varsegi GM, Shidham V. Cell Block Preparation from Cytology Specimen with Predominance of Individually Scattered Cells. Journal of Visualized Experiments. 2017;27(4):35-37.

7. Gill GW Arthur KL. Cell Block Preparation. In: Cytopreparation: Principles \& Practice. Journal of american society and cytopathology. 2018;5(78):131-142.

8. Mair S, Dunbar F, Becker PJ, Du Plessis W. Fine needle cytology; Is aspiration suction necessary? A study of 100 masses in various sites. J Acta Cytol. 2015;33(6):809-813. 
9. Gupta M, Gupta S, Gupta VB. Correlation of Fine Needle Aspiration Cytology with Histopathology in the Diagnosis of Solitary Thyroid Nodule. J Thyroid Res. 2017;45(8):1-5.

10. Bagga P, Mahajan N. Fine needle aspiration cytology of thyroid swellings: How useful and accurate is it? Indian J Cancer. 2010;47(4):437-445.

11. Basnet S, Talwar O. Role of cell block preparation in neoplastic lesions. J Pathol Nepal. 2018;2(4):2726.

12. Khan S, Omar T, Michelow P. Effectiveness of the cell block technique in diagnostic cytopathology. J Cytol. 2018;29(3):177-186.

13. Balassanian R, Wool GD, Ono JC, Olejnik-Nave J, Mah MM, Sweeney BJ, et al. A superior method for cell block preparation for fine-needle aspiration biopsies. Cancer Cytopathol. 2016;124(7):508-518.

14. Kamal MM, Arjune DG, Kulkarni HR. Comparative Study of Fine Needle Aspiration and Fine Needle Capillary Sampling of Thyroid Lesions. J Acta Cytol. 2015;46(1):30-34.

15. Garber JR, Cobin RH, Gharib H, Hennessey J V, Klein I, Mechanick Jl, et al. Clinical Practice Guidelines for Hypothyroidism in Adults: Cosponsored by the American Association of Clinical Endocrinologists and the American Thyroid Association. Thyroid. 2012;22(12):1200-1205.

16. Brown RL, de Souza JA, Cohen EEW. Thyroid Cancer: Burden of Illness and Management of Disease. J Can and Onc. 2017;2(87):193-199.

17. Thapar M, Mishra RK, Sharma A, Goyal V, Goyal V. Critical analysis of cell block versus smear examination in effusions. Journal of Cytology. 2019;56(8):60-64.
DATA SHARING STATEMENT: The data that support the findings of this study are available on request from the corresponding author. The data are not publicly available due to privacy or ethical restrictions.

CONFLICT OF INTEREST: Authors declared no conflict of interest.

GRANTED SUPPORT AND FINANCIAL DISCLOSURE: Nil

\section{AUTHOR'S CONTRIBUTION}

Following authors have made substantial contributions to the manuscript as under

Lal A, Ahmad S:

Concept and design of study, Collection of data, statistical analysis

Khan W, Orakzai SA: Writing of manuscript, critical review of manuscript

Faisal S: Analysis and interpretation of data, statistical analysis

Khan A: Data collection, bibliography

Authors agree to be accountable for all aspects of the work in ensuring that questions related to the accuracy or integrity of any part of the work are appropriately investigated and resolved. 